\title{
Stereoselective Glycosylations of 2-Azido-2-Deoxy-Glucosides using Intermediate Sulfonium lons
}

\author{
Jin Park, Sameer Kawatkar, Jin-Hwan Kim, and Geert-Jan Boons * \\ Complex Carbohydrate Research Center, University of Georgia, 315 Riverbend Road, Athens, GA \\ 30602
}

\section{Abstract}

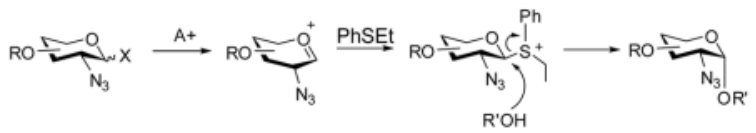

TMSOTf promoted glycosylations of 2-azido-2-deoxy-glucosyl trichloroacetimidates provide excellent $\alpha$-anomeric selectivities when performed at a relatively high reaction temperature in the presence of $\mathrm{PhSEt}$ or thiophene. NMR and computation studies have shown that these glycosylations proceed through an equatorial anomeric sulfonium-ion, which upon displacement by a sugar alcohol provides an axial glycoside. Computational studies have indicated that steric factors determine the selective formation of the $\beta$-anomeric sulfonium ion.

\begin{abstract}
The principal challenge presented by the synthesis of complex oligosaccharides of biological importance is the development of approaches for the stereoselective introduction of glycosidic linkages. A reliable method for stereoselective glycosylations is based on neighboring group participation of a 2-O-acyl functionality (Figure 1a). ${ }^{1}$ In these reactions, a promoter activates an anomeric-leaving group, which results in its departure and the formation of an oxacarbenium ion. Subsequent neighboring group participation of the 2-O-acyl protecting group will give a more stable dioxolenium ion. An alcohol can attack the anomeric center of the dioxolenium ion from only one face providing a 1,2-trans glycoside. Thus, in the case of glucosyl-type donors, $\beta$-linked products will be formed while mannosides will give $\alpha$-glycosides. The introduction of 1,2-cis glycosidic linkages, such as $\alpha$-glucosides and $\alpha$-galactosides, requires glycosyl donors with a non-assisting functionality at C-2. Invariably, the use of these glycosyl donors leads to the formation of mixtures of anomers. ${ }^{2,3}$ Separation of these anomers requires time-consuming purification protocols resulting in loss of material. It also limits the use of one-pot multi-step glycosylations $s^{4,5}$ and automated polymer-supported synthesis ${ }^{6-8}$ to oligosaccharides that only contain 1,2-trans glycosides. Thus, the stereoselective formation of 1,2-cis glycosides is the principal challenge of complex oligosaccharide synthesis.
\end{abstract}

Recently, we reported that a glycosyl donor substituted with a chiral auxiliary $9-11$ such as an $(S)$-(phenylthiomethyl)benzyl ether at C-2 can be employed for the stereoselective introduction of 1,2-cis glycosides such as $\alpha$-glucosides and $\alpha$-galactosides (Figure 1b). Neighboring group participation by the chiral auxiliary leads to a quasi-stable anomeric sulfonium ion. Due to steric and electronic factors, the sulfonium ion is formed as a trans-decalin ring system. Displacement of the sulfonium ion by a hydroxyl leads to the stereoselective formation of $\alpha$ glycosides. 
We report here that glycosylations of 2-azido-2-deoxy-glucosyl donors performed in the presence of a thioether provide glycosides with excellent $\alpha$-selectivity.

NMR and computational studies have shown that these glycosylations proceed through an intermediate sulfonium ion, which due to steric factors adopts an equatorial configuration. Displacement of the latter intermediate by a sugar hydroxyl results in the formation of an axial glycoside.

1,2-Cis-linked 2-amino-2-deoxy-glycosides are usually introduced by employing glycosyl donors having a non-participating azido moiety at $\mathrm{C}-2$ of a glycosyl donor. ${ }^{12,13}$ However, these glycosylations are rarely stereoselective and often provide mixtures of $\alpha / \beta$-anomers.

It was anticipated that the application of the auxiliary-based methodology for the preparation of $\alpha$-linked 2-amino-2-deoxy-glycosides would be difficult. Therefore, we investigated whether improvements in anomeric selectivities could be achieved by the addition of thioethers to glycosylations of 2-azido-2-deoxy-glycosyl donors. It was expected that activation of such glycosyl donors would lead to the formation of an oxacarbenium ion, which upon reaction with the thioether would give a sulfonium ion intermediate (Figure 1c). Due to steric factors the later intermediate should be formed as a $\beta$-anomer. Subsequent displacement of the $\beta$ sulfonium ion by a sugar hydroxyl should then give an $\alpha$-glycoside.

In the first instance, the effect of the addition of phenylthioethyl ether (PhSEt) on the anomeric outcome of TMSOTf-promoted glycosylations of 3,4,6-tri- $O$-acetyl-2-azido-2-deoxy-Dglucopyranosyl trichloroacetimidate $(\mathbf{1 a})^{14,15}$ with glycosyl acceptors 2-4 was investigated. Phenylthioethyl ether was selected due to its structural resemblance to the $(S)$ -

(phenylthiomethyl)benzyl ether auxiliary, which has been shown to glycosylate through a sulfonium ion.

Furthermore, primary sugar alcohols were selected because their use leads often to poor $\alpha$ anomeric selectivities. ${ }^{2}$ As can be seen in Table 1, the addition of PhSEt to glycosylations of 1a with 2-4 performed at $-78{ }^{\circ} \mathrm{C}$ in dichloromethane resulted in increases of $\alpha$-anomeric selectivities. Interestingly, when the reactions were performed at $0{ }^{\circ} \mathrm{C}$, further improvement of $\alpha$-selectivity was observed and in each case the addition of PhSEt gave the best results. For example, a TMSOTf promoted glycosylation of glycosyl donor $\mathbf{1 a}$ with glycosyl acceptor $\mathbf{2}$ in dichloromethane at $-78^{\circ} \mathrm{C}$ gave a poor anomeric selectivity of $\alpha / \beta=2 / 1$. An improved anomeric selectivity of $\alpha / \beta=5 / 1$ was achieved when the reaction was performed in the presence of PhSEt. Interestingly, increasing the reaction temperature to $0{ }^{\circ} \mathrm{C}$ resulted in a good $\alpha / \beta$ ratio of 8/1. However at this reaction temperature, the addition of PhSEt gave an excellent $\alpha$ anomeric selectivity of $\alpha / \beta=20 / 1$. The anomeric ratios were determined by integration of the signals of the methyl glycoside after purification by size exclusion column chromatography.

The observation that the addition of PhSEt led to improved $\alpha$-anomeric selectivities provides support that the glycosylations proceed through an intermediate $\beta$-sulfonium ion. In order to confirm the presence of this intermediate, glycosyl donor $1 \mathbf{a}$ and PhSEt (10 eq) in $\mathrm{CDCl}_{3}$ at $-20{ }^{\circ} \mathrm{C}$ were treated with one equivalent of TMSOTf and after a reaction time of 10 minutes, ${ }^{1} \mathrm{H},{ }^{1} \mathrm{H}$-TOCSY, HSQC and HMBC NMR spectra were recorded (Figure 2).

The collected data showed the formation of three compounds, which were unambiguously assigned as the $\alpha$-triflate $\mathbf{1 2}$ and two diastereoisomeric $\beta$-sulfonium ions 13. Thus, H-1 of compound 12 exhibits a large down-field shift and a small vicinal coupling constant between $\mathrm{H}-1$ and $\mathrm{H}-2$, which is typical for an $\alpha$-triflate $\left(\delta 6.50, \mathrm{~d}, J_{1,2}=3.5 \mathrm{~Hz}\right) .{ }^{16}$ On the other hand, the large vicinal coupling constants between $\mathrm{H}-1$ and $\mathrm{H}-2$ of the two other compounds indicated that their anomeric substituents have $\beta$-configurations $\left(\delta 5.95, \mathrm{~d}, J_{1,2}=10.0 \mathrm{~Hz} ; 5.48, \mathrm{~d}\right.$, $J_{1,2}=10.0 \mathrm{~Hz}$ ). Furthermore, the HMBC spectrum, which measures three-bond proton-carbon 
coupling, showed for each of the two compounds a correlation between H-1 and H-8 of the ethyl moiety of the aglycon, which demonstrates that $\beta$-sulfonium ions were formed. When the temperature of the sample was gradually raised to $0{ }^{\circ} \mathrm{C}$, signals arising from the $\alpha$-triflate and one of the $\beta$-sulfonium isomers disappeared and only peaks assigned to the other $\beta$ sulfonium isomer were observed. This compound exhibited a medium strong nuclear Overhauser enhancement (NOE) between H-1 and H-8. Furthermore, no NOEs were observed between $\mathrm{H}-1$ and the aromatic protons of the aglycon indicating that the phenyl substituent is trans to $\mathrm{H}-1$.

The three possible rotamers of the $\beta$-sulfonium ion were optimized by DFT quantum mechanical calculations. A distance of $2.8 \AA$ between $\mathrm{H}-1$ and $\mathrm{H}-8$ in the $t g$ conformation as in compound $\mathbf{1 3}$ is in agreement with the observed NOE. This conformation places the phenyl ring trans to $\mathrm{H}-1$ and explains the absence of NOEs between these protons. The $g g$ and $g t$ conformations predict NOEs between the aromatic ring of the aglycon and $\mathrm{H}-1$, which indicates that the $\beta$-sulfonium ion is preferentially formed as a $t g$ conformer.

Next, attention was focused on determining the origin of the stereoselective formation of the $\beta$-anomeric sulfonium ion. In this respect, it has been found that the equilibrium between anomers of pyranosides having a cationic functionality at their anomeric center often shifts toward the equatorial anomer, an effect that has been coined Reverse Anomeric Effect (RAE). Lemieux and co-workers explained the preferential formation of the equatorial anomer by stabilizing monopole-dipole interactions arising from the positive charge, which is close to the negative end of the dipole. ${ }^{17}$ However, this proposal fails to explain conformational preferences of several compounds which apparently are stabilized even though the positive charge has moved away from the negative end of the dipole. ${ }^{18}$ Finch and Nagpurkar proposed that RAE arises from a stabilizing homoallylic type overlap between the oxygen lone pair and $\pi^{*}$ orbital of the aromatic heterocycle, since such an overlap is geometrically favorable in an equatorial conformation. ${ }^{19}$ However, quantum mechanical calculations of the $N$ -

(hydroxymethyl)pyridinium ion indicated that the barrier to $\mathrm{C}-\mathrm{N}^{+}$rotation is at best $0.3 \mathrm{kcal} /$ mol when the $\mathrm{p}$ and $\pi^{*}$ orbitals are parallel. ${ }^{20}$ Moreover, UV spectra of 2-, 3-, or 4(hydroxymethyl)pyridinium ions showed no evidence for such a $\mathrm{p}-\pi^{*}$ orbital interaction. It appears that in these cases the $\beta$-anomer is preferred due to minimizing steric interactions. ${ }^{21}$

To examine the possible involvement of stereoelectronic effects in the preferential formation of $\beta$-anomeric sulfonium ions, molecular orbital calculations at the $\mathrm{B} 3 \mathrm{LYP} / 6-31 \mathrm{G}^{* *}$ level using the Jaguar program were performed on the $t g$ conformer (Figure 3). If stereoelectronic factors are responsible for stabilizing the $\beta$-sulfonium ion, overlap between the lone pair electrons of the endocyclic oxygen (p-orbital) with the $\pi^{*}$ orbital of the $\mathrm{C}-1-\mathrm{S}^{+}$bond would be expected. However, the calculations show that the HOMO-1 and LUMO molecular orbitals do not display any participation with the endocyclic oxygen. Thus, orbital interactions do not appear responsible for the greater stability of the $\beta$-sulfonium ion. Interestingly, a model of the axially substituted anomeric sulfonium ion in the $t g$ conformation demonstrates steric hindrance between the anomeric substitutent and $\mathrm{H}-3$ and $\mathrm{H}-5$ of the sugar ring. Thus, it is likely that the $\beta$-substituted sulfonium ion is selectively formed due to minimizing unfavorable steric interactions.

Having established that glycosylations performed in the presence of PhSEt proceed through a $\beta$-sulfonium ion intermediate, a number of thioethers were examined to improve the anomeric outcome of the glycosylations (see supporting information). As can be seen in Table 1, the use of thiophene resulted in further small increases in $\alpha$-selectivity.

Next, glycosyl donor 1a was coupled with secondary sugar alcohols 5 and 6 at $-78{ }^{\circ} \mathrm{C}$ and 0 ${ }^{\circ} \mathrm{C}$ in both the presence and absence of thiophene. In the case of $\mathbf{5}$, a small increase in $\alpha$ - 
anomeric selectivity was observed whereas the use of $\mathbf{6}$ gave in both conditions only the $\alpha$ anomer. The yields were relatively low in part due to the formation of substantial quantities of anomeric trichloroacetamide by-product due to reaction with the leaving group. ${ }^{22}$ When a thiophenyl glycoside was employed in combination with $\mathrm{Ph}_{2} \mathrm{~S}(\mathrm{O}) / \mathrm{Tf}_{2} \mathrm{O}$ as the promoter system, compounds 10a and 11a were obtained in better yields (see supporting information).

To demonstrate the generality of the approach, glycosyl donor $\mathbf{1 b}$ was coupled with $\mathbf{2 - 6}$ at $\mathbf{- 7 8}$ ${ }^{\circ} \mathrm{C}$ and $0{ }^{\circ} \mathrm{C}$ in the presence and absence of thiophene. As can be seen in Table 2, the $\alpha$-anomeric selectivity was improved when the glycosylations were performed in the presence of thiophene. Also, a relatively high reaction temperature improved the anomeric outcome of the glycosylations. The improvements were most notable when primary sugar hydroxyls were employed (table 2).

Finally, a number of glycosylations were performed with 2-azido-3,4,6-tri- $O$-benzyl-2-deoxyD-glucopyranosyl trichloroacetimidate ${ }^{22}$ (see supporting information). However, this glycosyl donor gave poor $\alpha$-anomeric selectivities for primary as well as secondary sugar alcohols. Furthermore, the addition of thiophene resulted only in marginal improvements of anomeric selectivity.

Probably, the high reactivity of the glucosyl donor promotes glycosylation of the intemediate oxacarbenium-ion resulting in poor anomeric selectivities.

In conclusion, glycosylations of 2-azido-2-deoxy-glycosyl trichloroacetimidates provide excellent $\alpha$-anomeric selectivities when performed at relatively high reaction temperatures in the presence of thiophene. Mechanistic studies have shown that activation of a trichloroacetimidate in the presence of PhSEt results in the formation of a $\beta$-substituted anomeric sulfonium ion. Computational studies have indicated that the steric factors determine the selective formation of the $\beta$-anomer. Displacement of the $\beta$-sulfonium-ion by an alcohol leads to the formation of an $\alpha$-glycoside. Finally, the use of highly reactive glycosyl donors leads to a reduction of $\alpha$-anomeric selectivity. Extension of the methodology to other glycosyl donors is in progress.

\section{Supplementary Material}

Refer to Web version on PubMed Central for supplementary material.

\section{Acknowledgements}

This research was supported by the National Institutes of Health (Grant No. R01GM065248 and 5P41RR05351).

\section{References}

1. Boons GJ. Contemp Org Synth 1996;3:173-200.

2. Demchenko AV. Synlett 2003:1225-1240.

3. Davis BG. J Chem Soc, Perkin Trans 1 1999:3215-3237.

4. Koeller KM, Wong CH. Chem Rev 2000;100:4465-4493. [PubMed: 11749355]

5. Douglas NL, Ley SV, Lucking U, Warriner SL. J Chem Soc, Perkin Trans 1 1998:51-65.

6. Plante OJ, Palmacci ER, Seeberger PH. Science 2001;291:1523. [PubMed: 11222853]

7. Seeberger PH, Haase WC. Chem Rev 2000;100:4349-4394. [PubMed: 11749351]

8. Kahne D. Curr Opin Chem Biol 1997;1:130-135. [PubMed: 9667837]

9. Kim JH, Yang H, Park J, Boons GJ. J Am Chem Soc 2005;127:12090-12097. [PubMed: 16117550]

10. Kim JH, Yang H, Boons GJ. Angew Chem Int Ed 2005;44:947-949.

11. Kim JH, Yang H, Khot V, Whitfield D, Boons GJ. Eur J Org Chem 2006:5007-5028.

Org Lett. Author manuscript; available in PMC 2008 September 11. 
12. Banoub J, Boullanger P, Lafont D. Chem Rev 1992;92:1167-1195.

13. Debenham J, Rodebaugh R, FraserReid B. Liebigs Ann-Recl 1997:791-802.

14. Grundler G, Schmidt RR. Liebigs Ann Chem 1984:1826-1847.

15. Jung KH, Muller M, Schmidt RR. Chem Rev 2000;100:4423-4442. [PubMed: 11749353]

16. Crich D, Sun SX. J Am Chem Soc 1997;119:11217-11223.

17. Lemieux RU, Morgan AR. Can J Chem 1965;43:2205-2213.

18. Dauben WG, Kohler P. Carbohydr Res 1990;203:47-56. [PubMed: 2224903]

19. Finch P, Nagpurkar AG. Carbohydr Res 1976;49:275-287.

20. Wu YD, Houk KN. J Am Chem Soc 1991;113:2353-2358.

21. (a) Handa T, Utena Y, Yajima H, Ishii T, Morita H. J Phys Chem 1986;90:2589-2596. (b) Randell KD, Johnston BD, Green DF, Pinto BM. J Org Chem 2000;65:220-226. [PubMed: 10813919] (c) Vaino AR, Szarek WA. J Org Chem 2001;66:1097-1102. [PubMed: 11312934] (d) Batchelor RJ, Green DF, Johnston BD, Patrick BO, Pinto BM. Carbohydr Res 2001;330:421-426. [PubMed: 11270822] (e) Perrin CL, Kuperman J. J Am Chem Soc 2003;125:8846-8851. [PubMed: 12862481] (f) Chan SSC, Szarek WA, Thatcher GRJ. J Chem Soc, Perkin Trans 2;1995:45-60.

22. Tsuda T, Nakamura S, Hashimoto S. Tetrahedron 2004;60:10711-10737. 
a) Classical neighboring group participation by C-2 ester leading to 1,2-trans glycosides

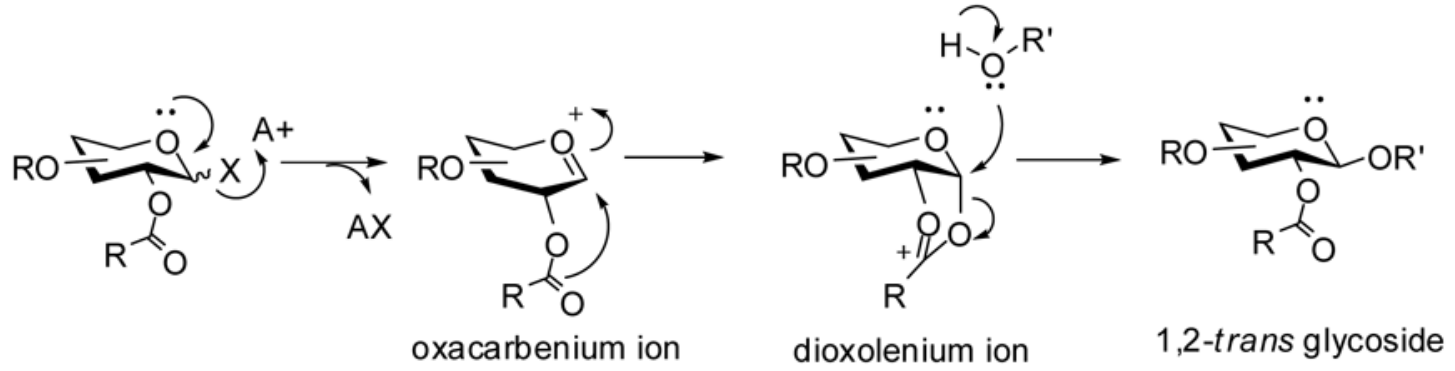

b) Neighboring group participation by C-2-(S)-auxiliary leading to 1,2-cis glycosides

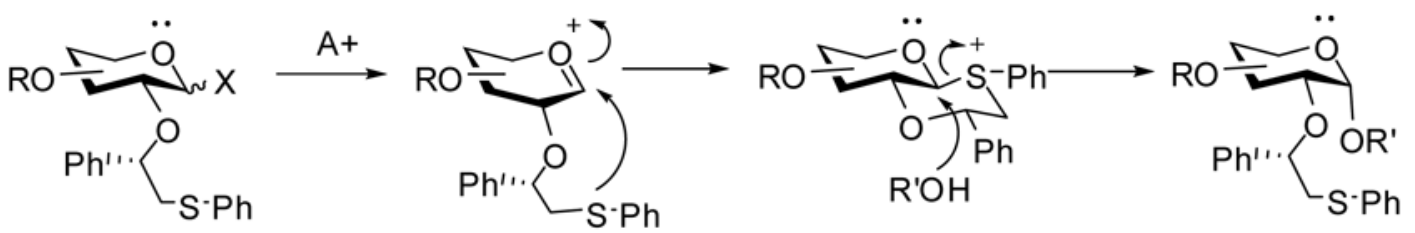

c) Sulfonium ion promoted glycosylation leading to 1,2-cis glycosides

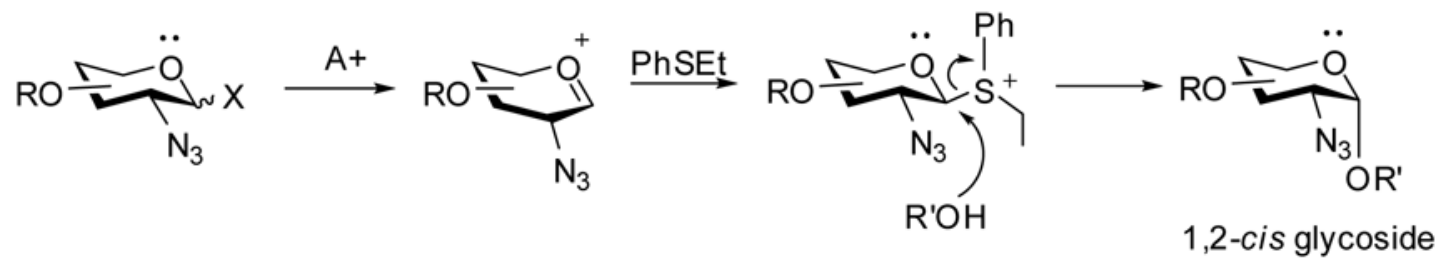

Figure 1.

Conventional and sulfonium ion promoted stereoselsctive glycosylation 
a)

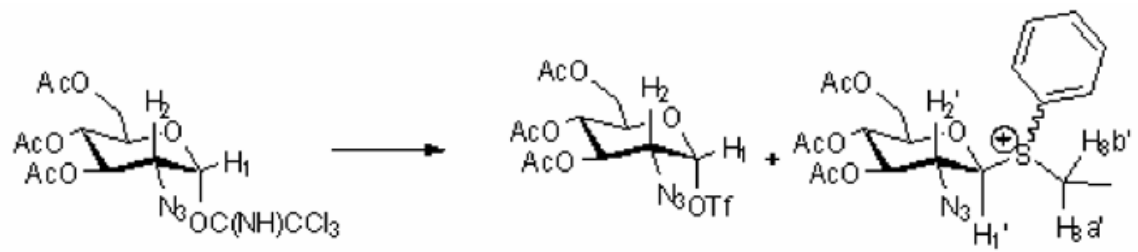

12

13

b)

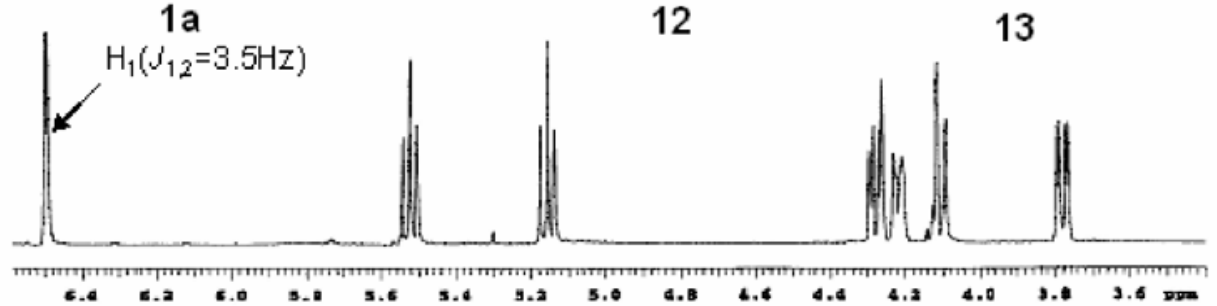

c)

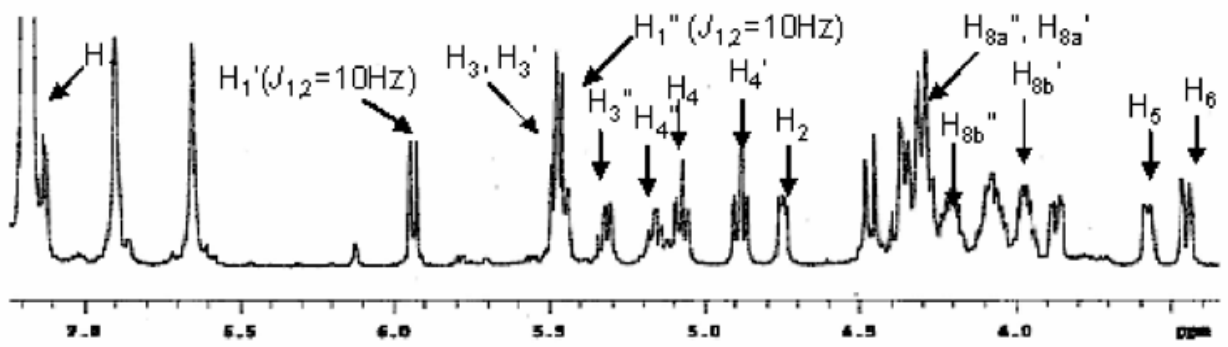

d)

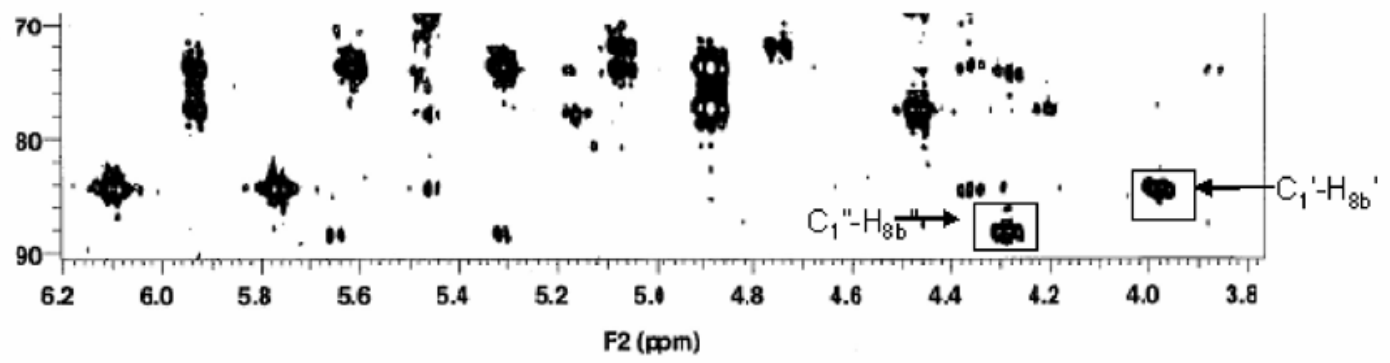

Figure 2.

a) The $\alpha$-triflate 12 and $\beta$-sulfonium ions 13 b) ${ }^{1} \mathrm{H}$ NMR spectrum of glycosyl donor $\left.1 \mathrm{a} \mathrm{c}\right){ }^{1} \mathrm{H}$ NMR spectrum of $\mathbf{1 2}$ and $\mathbf{1 3}$ d) HMBC spectrum of 12 and 13 

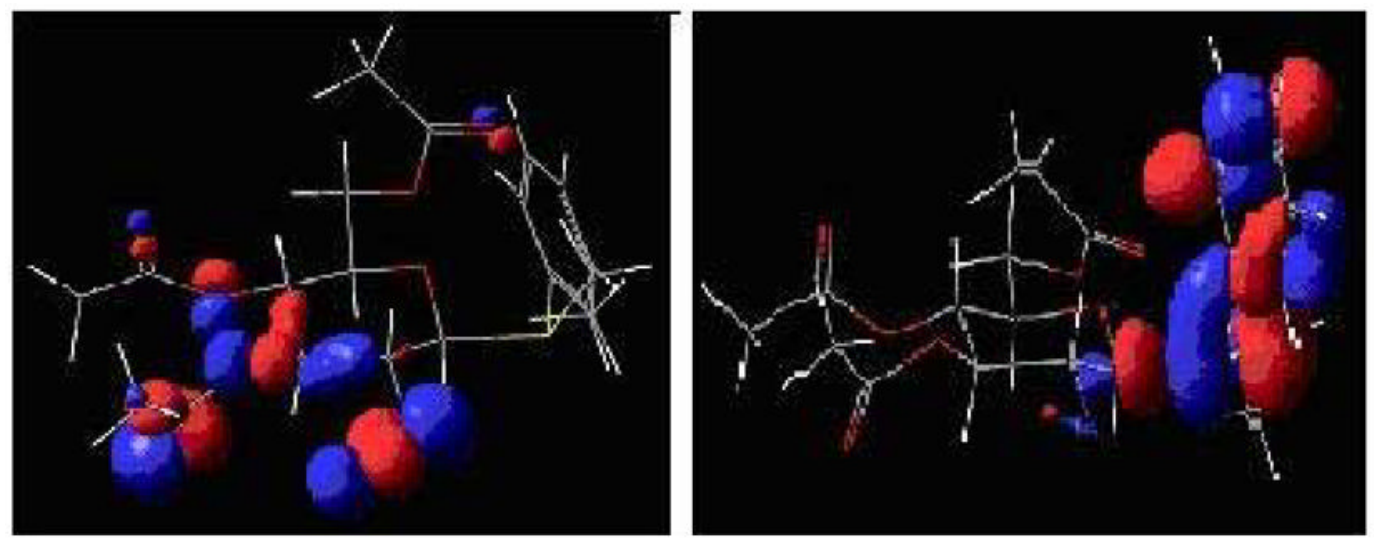

Figure 3.

HOMO- 1 and LUMO of $t g$ conformer of $\beta$-sulfonium ion intermediates. The endocyclic oxygen does not participate in any orbital overlap. These molecular orbital calculations indicate that stereoelectronic effects are not responsible and steric effects are the origin of selective formation of $\beta$-anomeric sulfonium ion. 


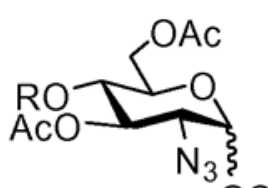

1a. $\mathrm{R}=\mathrm{Ac} \mathrm{OC}(\mathrm{NH}) \mathrm{CCl}_{3}$

1b. $R=B n$<smiles>COC1C2CCC(OC2(O)c2ccccc2)C(O)C1(O)c1ccccc1</smiles>

5

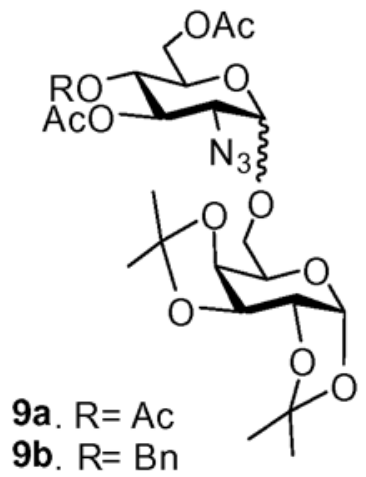

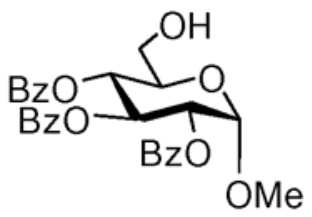

2

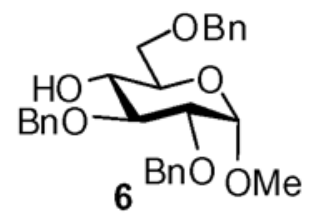

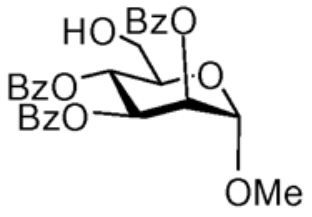

3
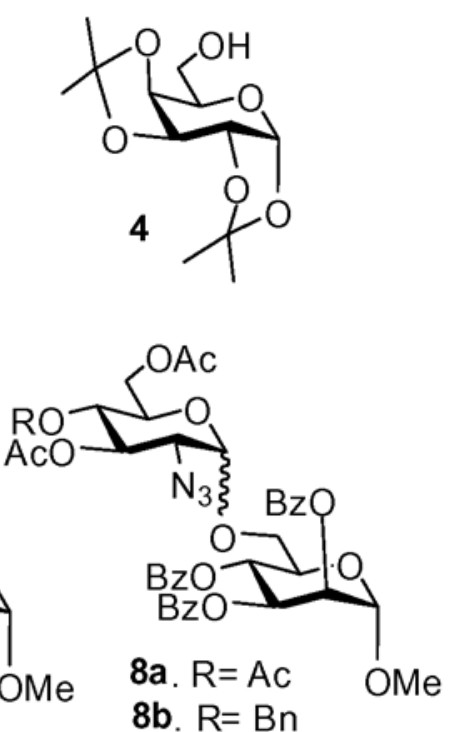

8b. $R=B n$

7a. $R=A c$
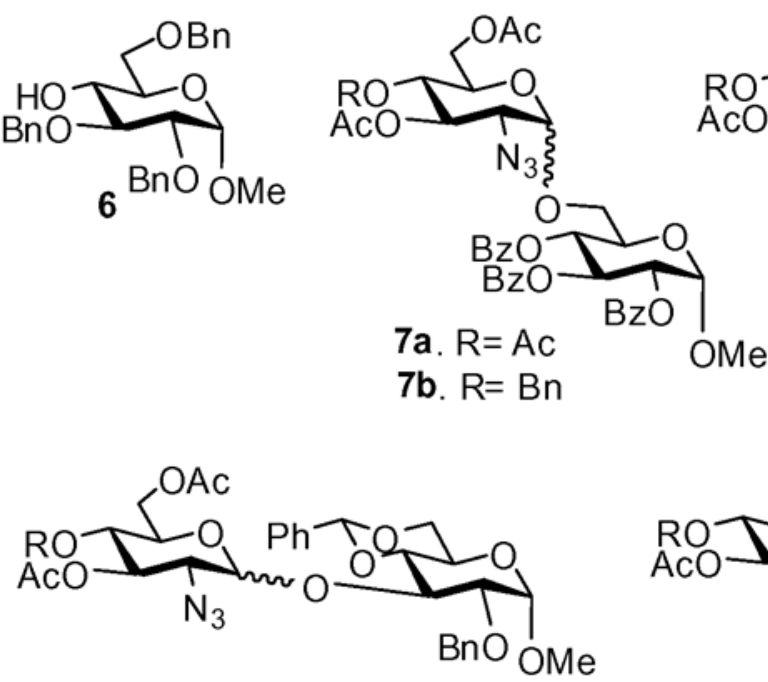

10a. $R=A c$

10b. $R=B n$

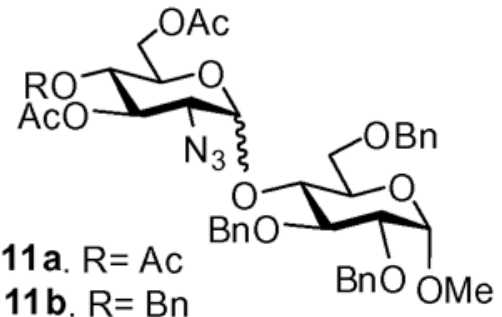

Scheme 1.

Glycosylations of glycosyl donors 1a, $\mathbf{b}$ and acceptors 2-6 
Table 1

Stereoselective outcomes of glycosylations of glycosyl donor 1a with glycosyl acceptors 2-6 in the presence or absence of a PhSEt or thiophene.

\begin{tabular}{|c|c|c|c|}
\hline acceptor & temp & thioether & product, $\alpha / \beta($ yield $)$ \\
\hline $\begin{array}{l}2 \\
2 \\
2 \\
2 \\
2 \\
2 \\
3 \\
3 \\
3 \\
3 \\
3 \\
4 \\
4 \\
4 \\
4 \\
4 \\
5 \\
5 \\
5 \\
5 \\
6 \\
6 \\
6\end{array}$ & $\begin{array}{r}-78^{\circ} \mathrm{C} \\
-78^{\circ} \mathrm{C} \\
0^{\circ} \mathrm{C} \\
0{ }^{\circ} \mathrm{C} \\
0{ }^{\circ} \mathrm{C} \\
-78^{\circ} \mathrm{C} \\
-78^{\circ} \mathrm{C} \\
0{ }^{\circ} \mathrm{C} \\
0{ }^{\circ} \mathrm{C} \\
0{ }^{\circ} \mathrm{C} \\
-78^{\circ} \mathrm{C} \\
-78^{\circ} \mathrm{C} \\
0^{\circ} \mathrm{C} \\
0^{\circ} \mathrm{C} \\
0{ }^{\circ} \mathrm{C} \\
-78^{\circ} \mathrm{C} \\
0^{\circ} \mathrm{C} \\
0^{\circ} \mathrm{C} \\
-78^{\circ} \mathrm{C} \\
0^{\circ} \mathrm{C} \\
0^{\circ} \mathrm{C}\end{array}$ & $\begin{array}{l}\text { None } \\
\text { PhSEt } \\
\text { None } \\
\text { PhSEt } \\
\text { Thiophene } \\
\text { None } \\
\text { PhSEt } \\
\text { None } \\
\text { PhSEt } \\
\text { Thiophene } \\
\text { None } \\
\text { PhSEt } \\
\text { None } \\
\text { PhSEt } \\
\text { thiophene } \\
\text { none } \\
\text { none } \\
\text { thiophene } \\
\text { none } \\
\text { none } \\
\text { thiophene }\end{array}$ & $\begin{array}{l}\mathbf{7 a}, 2 / 1(91 \%) \\
\mathbf{7 a}, 5 / 1(83 \%) \\
\mathbf{7 a}, 8 / 1(92 \%) \\
\mathbf{7 a}, 20 / 1(94 \%) \\
\mathbf{7 a}, \alpha \text {-only }(91 \%) \\
\mathbf{8 a}, 2 / 1(76 \%) \\
\mathbf{8 a}, 4 / 1(80 \%) \\
\mathbf{8 a}, 10 / 1(85 \%) \\
\mathbf{8 a}, 14 / 1(92 \%) \\
\mathbf{8 a}, 18 / 1(95 \%) \\
\mathbf{9 a}, 1 / 3(76 \%) \\
\mathbf{9 a}, 1 / 2(80 \%) \\
\mathbf{9 a}, 2 / 1(85 \%) \\
\mathbf{9 a}, 5 / 1(92 \%) \\
\mathbf{9 a}, 14 / 1(95 \%) \\
\mathbf{1 0 a}, 2 / 1(45 \%) \\
\mathbf{1 0 a}, 10 / 1(56 \%) \\
\mathbf{1 0 a}, 15 / 1(60 \%) \\
\mathbf{1 1 a}, \alpha \text {-only }(33 \%) \\
\mathbf{1 1 a}, \alpha \text {-only }(40 \%) \\
\mathbf{1 1 a}, \alpha \text {-only }(43 \%)\end{array}$ \\
\hline
\end{tabular}


Table 2

Steroeselective outcomes of glycosylations of glycosyl donor $\mathbf{1 b}$ with glycosyl acceptors 2-6 in the presence or absence of a PhSEt or thiophene.

\begin{tabular}{|c|c|c|c|}
\hline acceptor & temp & thioether & product, $\alpha / \beta$ (yield) \\
\hline $\begin{array}{l}2 \\
2 \\
2 \\
3 \\
3 \\
3 \\
3 \\
4 \\
4 \\
4 \\
5 \\
5 \\
5 \\
5 \\
6 \\
6 \\
6\end{array}$ & $\begin{array}{r}-78^{\circ} \mathrm{C} \\
0^{\circ} \mathrm{C} \\
0{ }^{\circ} \mathrm{C} \\
-78^{\circ} \mathrm{C} \\
0{ }^{\circ} \mathrm{C} \\
0{ }^{\circ} \mathrm{C} \\
-78^{\circ} \mathrm{C} \\
0{ }^{\circ} \mathrm{C} \\
0^{\circ} \mathrm{C} \\
-78^{\circ} \mathrm{C} \\
0^{\circ} \mathrm{C} \\
0{ }^{\circ} \mathrm{C} \\
-78^{\circ} \mathrm{C} \\
0^{\circ} \mathrm{C} \\
0^{\circ} \mathrm{C}\end{array}$ & $\begin{array}{l}\text { none } \\
\text { none } \\
\text { thiophene } \\
\text { none } \\
\text { none } \\
\text { thiophene } \\
\text { none } \\
\text { none } \\
\text { thiophene } \\
\text { none } \\
\text { none } \\
\text { thiophene } \\
\text { none } \\
\text { none } \\
\text { thiophene }\end{array}$ & $\begin{array}{l}\mathbf{7 b}, 5 / 1(85 \%) \\
\mathbf{7 b}, 12 / 1(90 \%) \\
\mathbf{7 b}, 20 / 1(93 \%) \\
\mathbf{8 b}, 4 / 1(90 \%) \\
\mathbf{8 b}, 10 / 1(95 \%) \\
\mathbf{8 b}, 20 / 1(92 \%) \\
\mathbf{9 b}, 4 / 1(90 \%) \\
\mathbf{9 b}, 10 / 1(98 \%) \\
\mathbf{9 b}, 15 / 1(96 \%) \\
\mathbf{1 0 b}, 3 / 1(40 \%) \\
\mathbf{1 0 b}, 11 / 1(52 \%) \\
\mathbf{1 0 b}, 15 / 1(50 \%) \\
\mathbf{1 1 b}, \alpha \text {-only }(31 \%) \\
\mathbf{1 1 b}, \alpha \text {-only }(35 \%) \\
\mathbf{1 1 b}, \alpha \text {-only }(37 \%)\end{array}$ \\
\hline
\end{tabular}

